\title{
IDAS E VENIDAS DE UM TORTO A BORDO DA LINGUAGEM: O TETRANETO DEL-REI, DE HAROLDO MARANHÃO
}

Alcmeno Bastos Universidade Federal do Rio de Janeiro

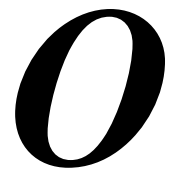

tetraneto del-Rei, ${ }^{1}$ de Haroldo Maranhão, é um romance histórico que discrepa do modelo tradicional, romântico antes de mais nada, por alguns aspectos que pretendemos aqui destacar. Inicialmente, abandona a dicção triunfalista, tratando a matéria de extração histórica - os primeiros tempos de colonização portuguesa no Brasil, na capitania de Pernambuco - com evidente intuito parodístico, ancorado num humor corrosivo que esvazia a heroicidade tradicionalmente atribuída aos vencedores. O protagonista, aliás, longe está de satisfazer as exigências do gênero, como se verá em seguida, a começar pelo jocoso apelido de "O torto" com que ganhou as páginas do registro histórico. A perspectiva do narrador não obedece ao distanciamento temporal canônico, avalizador do conhecimento superior e acabado que a voz narrativa do romance histórico clássico, situada num presente compartilhado com o leitor, demonstrava ter sobre a matéria narrada, tão necessária à construção de um certo exotismo temporal: falava-se de tempos, personagens e costumes idos, como tal estranhos ao leitor comum, de hoje. Em O tetraneto del-Rei, pelo contrário, o narrador coloca-se contemporaneamente à matéria narrada, e o instrumento por excelência dessa aproximação é a linguagem quinhentista por ele adotada, tanto no plano léxico

\footnotetext{
${ }^{1}$ MARANHÃO, 1982. Todas as citações de texto serão feitas com base nesta edição, com indicação, entre parênteses, das páginas correspondentes.
} 
quanto no plano sintático, que estabelece o efeito de autenticidade lingüística, sem prejuízo, porém, da recorrência a procedimentos discursivos típicos da modernidade, senão da pós-modernidade, tais como a intertextualidade alusiva. E ainda merece destaque o questionamento, por vias oblíquas, de uma entidade muito cara à historiografia tradicional, qual seja o peso da documentação escrita - das cartas, sobretudo -, aqui submetida ao confronto de seu teor com o do relato pela voz onisciente do narrador, testemunha privilegiada do acontecimento histórico.

O protagonista O tetraneto del-Rei é o português Jerônimo d'Albuquerque, cognominado O Torto, que chegou ao Brasil em 1534, na comitiva do cunhado, Duarte Coelho, primeiro donatário da capitania de Pernambuco, fundador de Olinda e pai de três filhos, um dos quais Jorge de Albuquerque Coelho, o festejado herói da Prosopopéia (1601) de Bento Teixeira. Deixou prole numerosa de seus dois casamentos: o primeiro, com Felipa de Melo; o segundo, sem que tenha desfeito o outro, com a índia Muira-Ubi, filha do morubixaba tabajara Arcoverde, de nome cristão Maria do Espírito Santo, casamento que lhe valeu o compreensível apelido de "Adão Pernambucano". Por todos os títulos, a posição histórica de relevo é do seu cunhado, casado com sua irmã, Brites de Albuquerque, mas de qualquer modo o protagonista de O tetraneto del-Reié personagem de extração histórica de alguma importância, tendo mesmo auxiliado a irmã no governo da capitania, quando da ausência de Duarte Coelho e até a maioridade do primogênito deste, Duarte Coelho de Albuquerque. ${ }^{2}$

A trajetória de Jerônimo d'Albuquerque, no romance, chega a ser pândega e está muito distante do modelo de herói oficial. Vem de Portugal e chega ao Brasil fugido de alguma provável vingança de marido enganado, já que na Corte era ele conhecido por suas proezas amorosas, "femeeiro excelentíssimo" que "nas recâmaras dava eficaz remédio às cortesãs que o privilegiavam" (p.10). Já lhe desagrada a posição secundária em relação ao cunhado, não ser ele

${ }^{2}$ MOTA, 1969. p.161-162. 
o comandante da frota, que naturalmente lhe parecia devida em razão de sua fidalga ascendência, e sim o outro: "Sangue por sangue, que sangue portava o Duarte, marido da irmã Brites?” (p.11), pergunta-se Jerônimo. O que ele ignora é que seu embarque para o Brasil, autorizado por decreto pelo rei, devia-se não apenas à ação de "um seu anjo tutelar" (p.10), como pensava, mas correspondia, na prática, a um degredo salvador, como, por fim, lhe revela o cunhado comandante, ao negar-lhe o direito de voltar a Portugal: "compete-me como capitão-mór e em nome del-rei testificar-vos que cá nestas terras estais e cá havereis de permanecer, privado do grão privilégio de ir-se e vir-se" (p.39).

Observa-se, assim, um desvio de ênfase na eleição do herói. Ao invés do poderoso donatário da capitania, um patético fidalgo cuja fama devia-se menos à sua ancestralidade - era descendente de Affonço de Albuqurque, o "valeroso de Ormuz, conquistador de benigníssima memória” (p.10), famoso por sua lança belicosa arremessada "aos peitos da ímpia gentilidade" (p.10) - e muito mais por ser dono de uma outra espécie de lança, que ele também ensopava, não no sangue dos inimigos, mas em sítios muito mais aprazíveis. O próprio cunhado, em tom jocoso, "dizia que jamais as costas lhe voltava: ao temor de ver-se trespassado, tal procedia ele às donzelas e às que não mais o fossem" (p.11). Sem ser propriamente um vencido, pois sua condição fidalga ainda lhe rendia privilégios em relação aos demais degredados, o protagonista de $O$ tetraneto del-Rei merece do narrador o primeiro plano não por seus feitos bélicos, mas pela proeza de um longo e doloroso aprendizado de colonizador em contato com a terra nova e o estranho povo que nela vivia. Jerônimo vai exercer um tipo de colonização muito diferente daquele que a história oficial e triunfalista consagrou. Sua vitória dá-se somente depois que ele, renunciando ao mundo de onde provinha e aos valores que norteavam suas ações, submetese à vontade dos inferiores, adapta-se ao espaço e sobrevive até o momento em que julga conveniente voltar para o seio dos brancos. Sua transformação é lenta, mas definitiva, e a primeira etapa desse processo é o olhar compreensivo lançado à própria terra: 
Ao cá aportar, estava na pele; e percebo que as benignidades que advêm da fresca do arvoredo alentam-me de carnes, avisos de que aqui, si, estão meus ares e aqui, si, está meu chão. A mim não me insufla a febre do ouro. A meu redor, olhos esbugalham-se no farejar riquezas encovadas, as nobres madeiras que são maciças florestas: quando a riqueza mor pode com as mão alcançar-se, colhendo-se fruitos sucosos e que de tão deleitosos extravasam da boca, tamanha a sofreguidão de gozá-los. (p.58)

Português era-o na cor e nos costumes; estes afeiçoavam-se a pouco e pouco às leis dos naturais. Tudo o mais ficara embrulhado às roupetas e às rendas, quando delas se desvencilhou. $\mathrm{Nu}$, raízes deitara ao chão umbroso. E a pele, a pele mesmo, branca não era mais, conquanto longe estivesse a brônzea cor; mas aqueles sóis tiraram o leitoso da epiderme chegada da Europa e diverso tom estava a impregnar-se-lhe. Lisboa era um sítio mais remoto que o céu. (p.183)

Seu casamento com a índia Muira-Ubi, por exemplo, se por um lado conjuga elementos clássicos do indianismo literário - a virgem índia que se apaixona pelo homem branco, renuncia à própria religião, aceita batizar-se e adotar nome cristão, e finalmente deixa a tribo para seguir com o marido em direção ao mundo dos brancos dominadores, quando este decide, por fim levá-la e ao filho por nascer para viverem em Olinda -, por outro não tem a ver com o dilaceramento interior do Martim de Iracema $^{3}$ entre a atração pela "virgem morena" e o amor pela "virgem loura", nem com o generoso impulso que leva o Diogo Álvares Correia de Caramuru 4 a impor o cristianismo aos selvagens mergulhados na trevas da impiedade, começando pela esposa Paraguaçu. A ligação de Jerônimo com Muira-Ubi é, de sua parte, solução pragmática: não esposasse ele a moça e acabaria, como outros brancos, no caldeirão fervente: "- Não me assam, mas me casam, o que pouco ou nada difere!” (p.180). Apenas seus privilégios de genro do morubixaba o livram do destino de outros portugueses, entre eles o próprio sacerdote que oficia a

3 ALENCAR, 1965.

${ }^{4}$ DURÃO, 1913. 
espetacular cerimônia de batismo cristão da jovem tabajara. Contudo, o casamento, apesar do evidente propósito utilitário, da parte de Jerônimo, o que também não impede que ele venha a estimar sinceramente a esposa tabajara, representa um decidido aceno de paz entre os dois povos.

A partir dessa escolha não canônica do herói, tudo o mais vai ser subvertido. Ao longo da narrativa, Jerônimo escreve cartas a uma "senhora" e nelas relata episódios nos quais se teria comportado com toda a bravura esperável de um europeu superior. Contrastando, porém com o teor das cartas, o relato dos mesmos fatos a cargo do narrador em terceira pessoa revela uma outra verdade, feita de covardia e brutalidade. O primeiro encontro dos portugueses com os índios, por exemplo, decerto não mereceria figurar em nenhuma crônica de feitos memoráveis. Jerônimo, que comandava o grupo, e vendo fracassada sua tentativa de estabelecer comunicação com a indiada, resolvera afrontá-los com o gesto de uma banana. Interpreta erradamente o silêncio que se segue à sua bravata, pensando "haver quebrantado a fereza daquela gente" (p.15), mas algumas inesperadas palavras saídas das fileiras indígenas, ditas em claríssimo português: "Nãããão! Bananas, nãããão!", levam os lusitanos à mais humilhante das reações: a fuga desordenada e fétida, como descreve o narrador: "E entraram uns a obrar-se, sem que pudessem pôr cobro àquelas vergonhosas demonstrações” (p.15). A mesma voz que reclamara das bananas, coroa a desmoralização do batalhão lusitano com este comentário lapidar: "- Quem tem cuuuuuuu tem meeeeedo1" (p.15). E o narrador, implacável, anota: "À frente do pugilo apavorado, corria justo o capitão, e em seu couce vinha obra de oitenta ou mais portugueses." (p.15).

Se assim se deram os fatos, na versão isenta do narrador onisciente, a carta de Jerônimo à sua "senhora", no entanto, conta outra estória, e nela o valoroso fidalgo não hesita em contrapor-se à audácia dos selvagens, repete o Caramuru, provocando "um trovão à mata", de modo que com "grandes clamores e brados, esta danada gente houve por bem escafeder-se à malfa, consumindo muitíssimo menos tempo em tornar ao de onde havia vindo" (p.17). Quanto aos 
companheiros de Jerônimo, ao invés de correrem esbaforidos, na versão epistolar mantiveram-se em "largo gargalhar, vendo sumirem pelos arvoredos c'os traseiros a trepidar, que se iam a tremer do susto que lhe pregáramos, um número infinito de cobardes que tão só vintoito" (p.18).

Supondo que as cartas de Jerônimo efetivamente chegassem a Portugal e fossem lidas pela "senhora" destinatária e por outras mais pessoas, ganhariam com certeza o distintivo de documentos bistóricos, dotados, portanto, da força convencional da palavra escrita, fonte primeira da historiografia tradicional. Entre as duas versões do episódio, caso alguma desgarrada testemunha ocular do acontecimento resolvesse restaurar a verdade, certamente o crédito seria dado à versão escrita. O narrador de O tetraneto del-Rei, limitando-se ao confronto por amostragem das duas versões, mas usando das prerrogativas da onisciência, desloca a verdade histórica do espaço onde ela normalmente é localizada - o documento escrito, chancelado pelo tom testemunhal - para o espaço não demarcado da história não-oficial. O valor documental das cartas é ainda afetado por um outro recurso ficcional, o sutil processo de esvaziamento da sua realidade, no nível mesmo da estória, pois Jerônimo continua a escrever suas cartas endereçadas à distante "senhora" mesmo depois de abandonar o "litoral" (título da primeira parte do romance, alusivo aos primeiros tempos da permanência do protagonista na terra nova) e se embrenhar pelos "matos" (título da segunda parte do romance, alusivo à segunda viagem de Jerônimo) e cair prisioneiro dos tabajaras, quando obviamente já não tem mais como remetê-las a Portugal. Numa dessas cartas, a antepenúltima, Jerônimo confessa empregar "tinta de orvalho, cálamo de raízes e papel de nuvens", na esperança de que "Um arcanjo quando estiver eu a dormir, levar-vos-á estas palavras minhas de amor e saudade" (p.161), patenteando assim a natureza abstrata das missivas. Como no caso das cartas anteriores (escritas com material convencional, supõe-se), o narrador não esclarecera se elas efetivamente haviam sido mandadas a Portugal, a ambigüidade permite-nos estender a todas as cartas de Jerônimo tal condição de inexistência. As cartas 
parecem ter sido estrategicamente dispostas na narrativa apenas para funcionarem como contraponto fantasioso da verdade, conhecida privilegiadamente pelo narrador. A suspeição atinge, portanto, não apenas a autenticidade das cartas de Jerônimo e seu status de possível fundamento de uma verdade histórica, mas toda a epistolografia da época da colonização, a começar pela própria Carta de Caminha. A leitura de tais documentos, sugere o narrador, deve ser feita com desconfiança, pois bem pode existir em cada uma delas apenas a fanfarronice imaginosa de outros tantos Jerônimos d'Albuquerques.

Se o Jerônimo d'Albuquerque ficcional é personagem impensável num romance histórico tradicional, seu cunhado Duarte Coelho, o poderoso donatário da capitania de Pernambuco, a despeito do suporte historiográfico mais respeitável (pelo menos não se lhe conhece nenhum apelido gaiato), também não escapa ao humor destrutivo que dá à narrativa inegável acento paródico. Do bom senso que norteia suas ações nos primeiros tempos descai até a completa insânia, como bem o percebe O Torto ("Está doudo, o Duarte de todo endoudeceu. Miserábil é o estado daquela cabeça, da qual todo o senso desertou." - p.70), culminando com a elaboração de um hilariante plano de guerra, a que dá o nome de "Cerca de Chumbo", uma formação em círculo com a qual, a uma ordem de comando, "os enemigos seriam dizimados a um tiro só" (p.90), um tiro "disparado por quinhentos, ou oitocentos ou mil ou mais" homens (p.90), mas de que resulta estúpida carnificina entre as linhas dos próprios portugueses, pois estes, dispostos em um círculo, todos atirando ao mesmo tempo, fatalmente atingiriam não aos índios, mas uns aos outros. Tanto quanto a insensata decisão de pôr em prática a tal "Cerca de Chumbo", o bizarro palavreado de Duarte Coelho incitando os subordinados é clara indicação de seu desvario:

- Ou é lobo ou rã, ou feixe de lenha ou arméu de lã. Calando se desonra quem com medo se cala. Razões aparentes destroem os estados. Custa pouco a Pedro beber a capa a Paio. Todo sangue é vermelho. Todo reino dividido será destruído. Em brigas, valer de pés. Até a morte, pé forte. Até o bem consultado, sabido dos 
inimigos, resulta em perigo próprio. Veremos quem cansa, se o asno ou quem o tange. Sem perigo não se faz façanha. Não entrar em barco de Cacilhas! Não, não, não entrar em barco de Cacilhas! Força é que eu vo-lo diga e rediga, uma, duas, bastas vezes: não entrar em barco de Cacilhas! (p.66)

Outras personagens, partícipes da colonização portuguesa em seus primórdios, são apresentadas em seus traços ridículos, como o vaidoso e ciumento morubixaba Arcoverde, sempre propenso a uma cerimônia pomposa, como o batizado cristão de sua filha MuiraUbi, desde que nelas lhe fosse reservado papel proeminente. Ou os demais portugueses, como o prolixo Ayres de Telo, o estúpido Calafurna, o desbocado Vasco Guedes, o alarmista Pio Palha Ribeiro (a quem Jerônimo oferece a oportunidade de escapar do caldeirão fervente, desde que concorde em ser seu padrinho de casamento, mas que nem por isso deixa de terminar seus dias como ingrediente principal do cozido indígena), e o imponente Padre Diogo Chichorro Sabugal, regente entusiasmado do batizado de Muiri-Ubi, e a quem o destino reserva também o fim culinário de tantos outros: o caldeirão fervente.

Nenhum índice de heroicidade consagrada resiste de pé, do mesmo modo que a selvageria dos indígenas não recebe qualquer justificativa enobrecedora. A antropofagia, por exemplo, é apresentada como um dado de realidade inquestionável, sem que se cogite do seu possível fundamento místico-religioso, como ocorre exemplarmente no "I-Juca-Pirama" de Gonçalves Dias. Aqui os prisioneiros são bem tratados, para que não morram magros e tão somente por estratégia culinária, como revela esta fala de Vasco Guedes, informando Jerônimo da dolorosa verdade de que os tabajaras eram antropófagos:

- Supus que o souberas, por mostrares-te cobarde face aos tipos que te cercaram. (...) Estou a ponto. Agora, estão a dar-me de beber um escuro caldo. Esse caldo, fico a imaginar que se preste a tornar tenras minhas carnes. Que sou este buzaranho de músculos. Por essa especial razão não me deitaram ainda a assar. A caldos próprios, contam molificar as viandas. Se a ponto ainda não estou, acerco-me. Já 
percebo uns olhares de gáudio que me põem, prelibando a deleitação que lhes darei. Terás tu percebido cúpidos olhares à tua volta? (p.141)

Nem o fato de acabarem todos no caldeirão fervente, com a pragmática exceção de Jerônimo, que a seu modo aplica uma espécie de "golpe do baú" cujo prêmio é a salvação da própria vida carnal, é motivo para que o narrador se entregue a dramáticas descrições dos sacrifícios humanos. Ora o leitor é informado indiretamente do fato, pela fala de uma personagem, dita com acento galhofeiro:

- Sim, dizer que o senhor Visconde do Cu Redondo foi competentemente assado ou cozido? Cozido, direi mais apropriadamente, que assado seria em grelhas e cozido é o que se deu, em caldeirão a ferver. Queriam ao visconde cozido e é de supor-se que bem o apreciaram. Pelo que se sabe, uns só poucos nacos restaram. (p.163)

relata uma das personagens, falando sobre a morte de Vasco Guedes, alcunhado de Visconde do Cu Redondo ("- Com cu ou sem cu foi escaldado a preceito, que os brutos são mimosos em caldeiradas e cozidos;" - p.163); ora a morte é mencionada incidentalmente, no meio de uma descontraída conversa:

Muitos, muitos anos depois, em distraída prática com Jerônimo, seu filho terceiro, por ele soube o Torto da baixa sorte do Padre Diogo Chichorro Sabugal.

- Não o sabias, pai? Pois disse-me a mãe há algum tempo que o padre que a batizara fora mandado cozer pelo pai dela e avô meu, à noite mesma do batismo. Verdade? não o sabias? (p.204)

O tom geral da narrativa é, assim, intencionalmente desprovido da ênfase rombuda do romance histórico tradicional. O tetraneto delRei pode ser visto como paródia desmi(s)tificadora da epicidade da colonização portuguesa no Brasil em seu momento inaugural. O indígena, em que pese a nenhuma idealização do seu retrato Muira-Ubi, por exemplo, não é de modo algum um portento de beleza: "Bonita não seria, mas qualquer traço apagava-lhe do rosto a vulgaridade da raça, o nariz chão, a escorrida cabeleira e até o fartum" (p.132), e seu pai é apenas um depósito cheio de fatuidade -, é 
preservado na integridade de seus estranhos costumes. A recusa à idealização não esconde, porém, a condição de vítimas dos naturais da terra. Fica patente, sobretudo pela fala de algumas personagens, que foi a empáfia ignorante do europeu a culpada pela abertura das hostilidades entre eles e os nativos:

- Sinto trazer-te más novas. Que os nossos endoudaram. Endoudaram os capitães e endoudaram os soldados, estes copiando o exemplo do alto. Olha, Albuquerque, os índios são obra dos brancos. (...) Os capitães nossos traem, mentem, mistificam. (...) mas a guerra não é justa, a guerra é injustíssima, que estão as razões com o gentio. (...) A cobiça ensandeceu os nossos mais eminentes, que usam dos índios que podem, tomando rendidos por cativos, e os que não podem, açoitam e matam. (...) A reação dos naturais a todas estas indignidades é justa, é justa a sua guerra. (p.149-150)

Para esse rebaixamento de tom contribui enormemente a linguagem quinhentista do narrador de O tetraneto del-Rei. Tal dicção não representa apenas virtuosismo estilístico, mas o rompimento, no nível do discurso, com uma das convenções mais típicas do romance histórico tradicional: o distanciamento temporal do narrador, veiculado lingüisticamente, em relação à matéria narrada. Ao invés das rubricas denunciadoras do abismo temporal - "naquele tempo", "no ano distante de...", em "épocas remotas" etc. -, cômodo recurso de afirmação de uma superioridade cognitiva do narrador em relação à matéria narrada, a viagem no tempo rumo ao passado faz-se no interior da linguagem, pela absorção de uma dicção contemporânea dos fatos narrados. A perspectiva temporal do narrador é a do presente em relação à matéria narrada, deixandose enformar pelo léxico e pela sintaxe da época em que se teriam dado os fatos, como se fora ele um dos participantes da ação e não alguém que, passado muito tempo, debruça-se generosamente sobre os tempos idos e o resgata do esquecimento:

Mui devagar, a grácil caravela demandou em direitura da praia. Que isenta de pessoas estava, tampouco de animais outros, como se em tais terras tão só houvesse árvores, areia e água, salvante os pássaros, que revoavam havia algum tempo em distância de uma milha ou duas. 
O capitão especulou o bonançoso lugar, percorrendo-o de lés a lés, com a luneta; e afiou os sentidos a averiguar se divulgava vultos ou rumores de gente percebia. Sabendo embora que os habitadores da terra receberam os conquistadores antecedentes em boa amizade, disse entre si o cauto capitão, muito avisado dessas matérias: gentio é gentio, mais próximo às feras que aos seus semelhantes. (p.13)

Separado do texto, o pastiche acima pode muito bem levar um leitor apressado a acreditar que se trata da transcrição de um trecho de alguma das crônicas que dizem dos primeiros tempos do Brasil. É notável que o domínio artesanal da linguagem não seja episódico, e sim a constante nas mais de 200 páginas do texto. Mais notável ainda que uma linguagem assim vazada suporte, sem deixar a impressão de quebra de unidade, também o registro em baixo calão, seja no erotismo das cartas de Jerônimo à sua "senhora", nas quais as alusões obscenas ainda estão veladas pelo vocabulário culto:

Tanto me abraso com a presença vossa quase tangível, que a mi se me antolha o sorriso vosso nas insônias que me pungem. E então, cresce-me, sem que possa opor qualquer disfarce, o vosso só vosso cetro especialíssimo, que um dia porfiou que havia de cativar vossos favores. Ah! Senhora! Ardo-me de febres e queima-me a minha e vossa vergôntea, provada em carnificinas. (...) E de ferro seria eu se não lhe acudisse nas sumas instâncias e mentidor poderíeis chamarme se não o experimentasse neste novo gênero de refrega. Não a derribaria eu, a lança insigne, se em rédea não me centrasse no solitário culto ao prestimoso e sábio Onan. Cujo milagre é apoucar em obra de minuto um gigante à altura do anão. A minha deleitação consignai vós ao mérito vosso, e o benigno sono que em seguida me advém, tão notavelmente aliviado. Tenho que doravante sereis lembrada bastas vezes, nas minhas noutes de tribulação e para as quais logrei depara socorro pronto. (p.12-13)

seja nas falas ou nas exclamações das personagens, quando o palavreado chulo explode sem disfarces, harmoniosamente casado com o comentário do narrador:

- Caralho!

A rascante invocação dizia do seu estado d'ânimo, a meio palmo e só de endoudecer, eriçado de neurastenias, as quais são adubado 
chão para prosperarem insanas idéias. Por aqueles meios ia dar a um muro, que luz algũa trespassasse. (p.37)

Contudo, o quinhentismo da linguagem não obsta o emprego de recursos da modernidade, senão da pós-modernidade, como o da intertextualidade alusiva, que permite ao texto o simultâneo diálogo com as fontes com que ele finge confundir-se e com outros textos do repertório do leitor de nossos dias. Em Nota do Autor, colocada no fim do volume, fala Haroldo Maranhão dos "enxertos" de textos alheios de que lançou mão, numa diversidade estilística e cronológica que não respeita períodos literários nem nacionalidades, juntando numa mesma família

Fr. Amador Arrais, Pero Vaz de Caminha, Camões, Bocage, Gregório de Matos, Frei Francisco de Mont'Alverne, Camilo Castelo Branco, Antero de Quental, Eça de Queiroz, Machado de Assis, Francisco Otaviano, Olavo Bilac, Fernando Pessoa, João Guimarães Rosa, Manuel Bandeira, Carlos Drummond de Andrade, João Cabral de Melo Neto, Mário Faustino e Ledo Ivo. (p.211)

Dentre tantos nomes que terão contribuído com "enxertos", Camões é um caso à parte. Presente em vários momentos da saga d'O Torto (p.31-32, 48, 85, 117, por exemplo), funciona como premonição de destino para Jerônimo, que sonha com o poeta sem o conhecer bem ("um poeta que uma vez vira transitar em Goa, Luiz Vaz..., Luiz Vaz..., cria o Torto que se apelidava o poeta de Luiz Vaz de C, ou Camães, ou Camões" - p.31), estranho sonho no qual a cabeça de Camões, com seu olho vazado, como futuramente virá a acontecer também a Jerônimo, aparece sobre o corpo do fidalgo, "o solitário olho nele empregado a modo sobressaltado, tal desejasse explicar-lhe matéria de significação certamente" (p.32). Quanto aos demais autores e algumas de suas obras, as alusões são cifradas, disseminadas ao longo do texto, às vezes quase imperceptíveis ("- Fogo morto? Pedra do sono?"), outras feitas nominalmente, como nos casos de Mário Faustino e João Cabral de Melo Neto:

Na selva cor da vida atalhos vibram. Mário: que tão cedo te partiste! Mário fausto; Mário faustino! Na selva cor da vida atalhos vibram (...) 
De qual João escutei esta voz?, de um Cabral amantíssimo amante de rios!: em qualquer viagem o rio é o companheiro melhor. A um rio sempre espera um rio mais vasto e ancho mar. (p.113)

sempre sem destaque gráfico no texto, cabendo ao leitor a descoberta da origem. São versos de Fernando Pessoa: "Toma-me um pouco o delírio das coisas marítimas" (p.46), da Ode marítima; são fragmentos de versos, como a referência à "Última flor do Lácio" de Olavo Bilac etc. Essa abundante família literária, que mistura brasileiros e portugueses na mesma aventura lingüístico-literária, serve também para tirar de O tetraneto del-Rei qualquer ranço nacionalista, em mais um desvio da tradição ufanista, não sendo indevida a afirmação de Benedito Nunes, feita na "orelha" desta edição, para quem as aventuras de Jerônimo d'Albuquerque "também são as da língua portuguesa, protagonista da história tanto quanto o Torto o é da linguagem”.

\section{Referências Bibliográficas}

ALENCAR, José de. Iracema (Lenda do Ceará). Edição comemorativa do centenário. Fortaleza: Imprensa Universitária do Ceará, 1965.

DURÃO, Fr. José de Santa Rita. Caramuru: poema épico do descobrimento da Babia. Rio de Janeiro: Garnier, 1913.

MARANHÃO, Haroldo. Otetraneto del-rei (O torto: suas idas e venidas). Rio de Janeiro: Francisco Alves, 1982.

MOTA. Fernando de Oliveira. Introdução. In: PILOTO, Afonso Luiz \& TEYXEYRA, Bento. Naufragio E Prosopopea. Recife: Universidade Federal de Pernambuco, 1969. 


\section{Resumo}

O romance histórico O tetraneto del-rei (O torto: suas idas e venidas), de Haroldo Maranhão afasta-se do modelo de romance histórico tradicional em alguns aspectos. Não adota uma dicção triunfalista, tratando a matéria de extração histórica - os primeiros tempos da colonização portuguesa no Brasil - com intuito parodístico. Elege como herói uma figura cuja vitória decorre da renúncia aos valores do mundo branco e da adaptação sofrida à terra nova. E adota uma dicção quinbentista, anulando o distanciamento temporal entre o narrador e a matéria narrada, sem prejuízo da adoção de procedimentos discursivos da modernidade, como a intertextualidade alusiva.

\section{Abstract}

The historic novel O tetraneto del-rei The King's Great-GreatGreat Grandson (The Crooked One: His Comings and Goings\}) by Haroldo Maranhão departs from the traditional historic novel model in some aspects. It does not adopt a triumphant diction, treating its historic subject matter - the initial period of Portuguese colonization in Brazil - as a parody. Its chosen hero is a character whose victory is a result of his renouncing the white world's values and his suffering in adapting to the new land. Indeed the novel adopts a 1500's diction, eliminating the temporal distance between the narrator and the narrated matter, while at the same time adopting modern discursive procedures, such as allusive intertextuality. 